Stortenbeker, J.A., Houwen, J., Lucassen, P.L.B.J., Stappers, H.W., Assendelft, W.J.J., Dulmeng S. van, Olde Hartman, T.C., Das, E. Quantifying positive communication: doctor's language and patient anxiety in primary care consultations. Patient Education and Counseling: 2018, 10149), 7 1577-1584

\begin{tabular}{|l|l|}
$\begin{array}{l}\text { Postprint } \\
\text { Version }\end{array}$ & 1.0 \\
\hline Journal website & https://linkinghub.elsevier.com/retrieve/pii/S0738-3991(18)30199-X \\
\hline Pubmed link & $\underline{\text { https://www.ncbi.nlm.nih.gov/pubmed/29751948 }}$ \\
\hline DOI & $10.1016 /$ j.pec.2018.05.002
\end{tabular}

This is a NIVEL certified Post Print, more info at http://www.nivel.eu

\title{
Quantifying positive communication: Doctor's language and patient anxiety in primary care consultations
}

INGE A. STORTENBEKER ${ }^{\text {A }}$, JUUl HOUWEN ${ }^{\mathrm{B}}$, PETER L.B.J. LUCASSEN ${ }^{\mathrm{B}}$, HugO W. STAPPERS ${ }^{\mathrm{B}}$, WILLEM J.J. ASSENDELFT ${ }^{\mathrm{B}}$, SANDRA VAN DULMEN ${ }^{\mathrm{B}, \mathrm{C}, \mathrm{D}}$, TIM C. OLDE HARTMAN ${ }^{\mathrm{B}}$, ENNY $\mathrm{DAS}^{\mathrm{A}}$

${ }^{a}$ Centre for Language Studies, Radboud University, Nijmegen, the Netherlands

${ }^{\mathrm{b}}$ Department of Primary and Community Care, Radboud University Medical Centre, Nijmegen, the Netherlands

${ }^{c}$ NIVEL (Netherlands institute for health services research), Utrecht, the Netherlands

${ }^{d}$ Faculty of Health and Social Sciences, University College of Southeast Norway, Drammen, Norway

\section{HighLIGHTS}

- This study systematically disentangles content from message directness in messages of GPs.

- GPs express more direct positive and indirect negative messages in communication with patients with MES but not MUS.

- The use of direct negative messages is related to an increase in patient anxiety.

\footnotetext{
AbSTRACT

Objective: Positive communication is advocated for physicians during consultations with patients presenting medically unexplained symptoms (MUS), but studies generally focus on what is said rather than how it is said. This study quantified language use differences of general practitioners (GPs), and assessed their relation to patient anxiety.

Methods: Language use of 18 Dutch GPs during 82 consultations was compared for patients with MUS versus medically explained symptoms (MES). Message content (positive or negative) was differentiated from its directness (direct or indirect), and related to changes in patient's state anxiety (abbreviated State Trait Anxiety Inventory; STAI).

Results: In total, 2590 clauses were identified. GPs approached patients with MES with relatively more direct (vs. indirect) positive and indirect (vs. direct)
} 
Stortenbeker, J.A., Houwen, J., Lucassen, P.L.B.J., Stappers, H.W., Assendelft, W.J.J., Dulmeng S. van, Olde Hartman, T.C., Das, E. Quantifying positive communication: doctor's language and patient anxiety in primary care consultations. Patient Education and Counseling: 2018, 10149), 1577-1584

negative messages (OR $0.53 ; 95 \%$ CI $0.39-0.710$ ). Anxiety of both patient groups increased when GPs used more direct (vs. indirect) negative messages $(b=0.67,95 \%$ CI $0.07-1.27)$

Conclusions: GPs use different language depending on the content of messages for patients with MES, but not MUS. Direct negative messages relate to an increase in patient anxiety.

Practice implications: GPs could manage patient's state anxiety by expressing negative messages in an indirect rather than direct manner.

\section{INTRODUCTION}

Research on doctor-patient communication has shown that interactions with health care providers can lead to patients experiencing changes in health outcomes that are not directly related to the medical treatment itself [1]. For instance, positive verbal suggestions are a strong predictor of pain decrease when patients need to undergo an invasive procedure [2] or when they are provided with pain relief [3] ; [4]. A physician's positive (versus negative) communication style has been found to lead to a better recovery [5], and raising positive expectations about treatment outcomes appears to decrease pain experiences [6] and to increase illness outcome expectancies; a strong predictor of health outcomes [7]. Conversely, negative health effects can emerge when, for instance, patients receive warning messages about medical procedures [2], or when they receive information about potential side effects of a treatment [8]. Evidence thus suggests that communication can lead to an improvement or worsening of health outcomes. Previous studies mainly examined variations in message content. For instance, an early - and often cited - study by Thomas studied effects of doctor-patient communication on patient outcomes by providing a different diagnosis and prognosis [9]. The study reported communication effects by comparing very diverse experimental conditions, which could not be replicated in a later study[10]. Moreover, research compares effects of messages such as "It will sting a little bit" with no warning messages during medical procedures [2], or effects of receiving information about pain relief versus no information [6]. These findings indicate that messages with different contents have an effect on health outcomes.

A key problem in such variations in message content is that they affect the meaning of a message. This study will define positive or negative communication in terms of language (how it is said) rather than message content (what is said). Differences in language use can change the directness of a message while keeping its content stable. For example, when warning a patient about an upcoming injection, physicians could use different language by saying that "it could give an unpleasant feeling" rather than "it will sting a little bit". Here, the message's content is similar (the patient is warned), but it is formulated with different and more indirect wordings. Thus far, few empirical studies systematically compared differences in physician language use. The objective of this study is to extend previous research by disentangling message content from message directness in medical consultations, and to build towards a quantification of 'positive communication'.

Language use of physicians can have an impact on patients visiting general practice. Framing research shows that different wordings to describe logically equivalent concepts, e.g. "a success rate of $40 \%$ " or "a failure rate of $60 \%$ " lead to differences 
Stortenbeker, J.A., Houwen, J., Lucassen, P.L.B.J., Stappers, H.W., Assendelft, W.J.J., Dulmeng S. van, Olde Hartman, T.C., Das, E. Quantifying positive communication: doctor's language and patient anxiety in primary care consultations. Patient Education and Counseling: 2018, 101(9), 7 1577-1584

in patient outcomes. Positively framed information could, for instance, make patients feel less anxious [11] or increase perceived treatment efficacy [12]. Moreover, preliminary evidence suggests that variations in language use during doctor-patient interactions can evoke difference cognitive and emotional reactions [13] ; [14]. Individuals would generally have more positive outcome expectancies when they hear that their quality of life is "likely to improve" instead of "not likely to deteriorate" [14].

Language use is especially relevant in consultations with patients presenting symptoms that cannot be attributed to detectable underlying diseases. Such medically unexplained symptoms (MUS) are common, with numbers of persistent MUS in general practice varying from 3 to $11 \%$ [15] ; [16], and from 1.5 to $20.2 \%$ in medical specialities [17] ; [18]. The absence of a clear organic cause in MUS challenges communication between doctors and patients. Physicians find it difficult to explain symptoms [19], and to provide appropriate care for patients with MUS [20]. They are less empathic with these patients [21], and they pay less attention to symptom explorations when patients present symptoms that are likely to be unexplained as opposed to symptoms that have a somatic cause [22]. Patients with MUS generally feel more anxious and not taken seriously [23] ; [24].

Assessing communication patterns is necessary because effective medical treatment are lacking for most of patients with MUS. Previous studies show that explanations of unexplained symptoms tend to be unclear, tentative and uncertain [25], with use of indirect formulations (e.g. "it is not an epileptic seizure") [26] and vague labels (e.g. "counselling" instead of "psychotherapy"). Patients often react defensively towards psychosomatic explanations of symptoms [24]; [27]. The possibility exists that linguistic expressions used in these consultations contribute to these patients feeling stigmatised [28] and dissatisfied [29]. However, no empirical studies systematically compared quantitative differences in physician language use for patients with medically unexplained or explained symptoms, nor have these related language use to patient outcomes in a naturalistic setting.

The aim of the present study is twofold. First, to assess whether GPs use different language when communicating with patients with MUS or with patients with medically explained symptoms (MES) by quantitatively comparing physicians' language use in terms of message content and its directness. Second, to explore how directness in doctors' messages relates to changes in anxiety assessed after a consultation to the general practitioner.

\section{METHODS}

This naturalistic study compared the communication of general practitioners (GPs) towards patients with MUS and patients with MES, and examined its relation to patient anxiety.

\subsection{Participants and setting}

One of the researchers $(\mathrm{ToH})$ contacted Dutch GPs in the area of Nijmegen to ask for participation in a video consultation study. Twenty out of the 36 approached GPs agreed to participate. Consultations with GPs and patients were recorded for the course of one or two days from April to September 2015 [30]. Patients who agreed to participate were provided a written informed consent. Procedures were approved by the research ethics committee of the Radboud University Medical Centre. 
Stortenbeker, J.A., Houwen, J., Lucassen, P.L.B.J., Stappers, H.W., Assendelft, W.J.J., Dulmeng S. van, Olde Hartman, T.C., Das, E. Quantifying positive communication: doctor's language and patient anxiety in primary care consultations. Patient Education and Counseling: 2018, 10149), 1577-1584

In total, 393 of 509 patients visiting their GP agreed to participate in the study. Dutch speaking patients older than 18 years were eligible for study participation. In a postconsultation questionnaire, the GPs had to indicate whether they thought patients had MUS, partial MUS or MES [21] ; [31]. Based their judgments, symptoms of 43 patients were labelled as MUS, 36 as partial MUS and 314 as MES. In order to compare communication of GPs for patients with MUS and MES, each patient with MUS was linked to a patient with MES visiting the same practitioner at the same day, following a similar method performed by Salmon, Ring, Dowrick and Humpris [32]. Patients with partial MUS were excluded because the main focus of the study was to analyse GPs' language use with patients with definite MUS or MES.

Consultations of the sample were transcribed with verbatim transcription methods (personal identifiers removed).

\subsection{Patient questionnaires: state anxiety measure}

Patients filled in a questionnaire before and after the consultation that assessed patient anxiety with the shortened version of the State Trait Anxiety Inventory (STAI) [33]. Ten four-point Likert scaled statements (before consultation, $\alpha=0.88$, after consultation, $\alpha=0.91$ ) concerning patients' anxiety, such as "I am worried", "I feel calm", and "I feel nervous", had to be completed with answering options varying from "not at all" to "very much so".

\subsection{Coding procedure and reliability}

To analyse GPs' language use, a codebook was developed that described criteria for categorisation of clauses that were relevant for inclusion. The codebook was created based on observations of the video data, complemented with existing linguistic literature on, for instance, the use of negations [34] ; [35]. Previous versions of the codebook were refined by testing its specificity (coding too specific or vague) and comprehensibility (all relevant clauses included) on videos from the corpus, and after discussions in research group meetings. The final coding procedure was divided into two steps. First, two coders identified clauses relevant for inclusion out of a subset of 18 consultations (i.e., $21 \%$ double coded). Clauses of the GPs about patients and their medical situation were identified. These related to comments about the patient's physical or mental state during physical examination, the (explanation of) the diagnosis, or the treatment policy and expected outcomes. Krippendorff's Alpha $\left(\alpha_{k}\right)$ was used as a measure of inter-coder reliability. After having identified clauses relevant for inclusion $\left(N=2249, \alpha_{\mathrm{k}}=0.62,95 \%\right.$ CI 0.40 to 0.79$)$, both coders categorised language use in terms of content and directness out of the clauses selected by the first coder from the same subset $(n=503)$. As an example, positive messages could be expressed directly (e.g. "your symptoms are benign"), or indirectly (e.g. "your symptoms are not malignant"). Similarly, messages with negative content could be expressed in a direct (e.g. "your symptoms are malignant"), or indirect (e.g. "your symptoms are not benign") manner. Clauses were categorised in terms of consultation phase (physical examination, diagnosis, or treatment recommendations; $\alpha_{\mathrm{k}}=0.71,95 \%$ CI 0.63 to.79), message content (positive, negative, or neutral; $\alpha_{\mathrm{k}}=.86,95 \%$ CI 0.81 to 0.89 ), and message directness (direct or indirect; $\alpha_{\mathrm{k}}=.94,95 \%$ CI 0.88 to 0.98 ). More information on the coding procedure is provided in the technical appendix (Appendix A). 
Stortenbeker, J.A., Houwen, J., Lucassen, P.L.B.J., Stappers, H.W., Assendelft, W.J.J., Dulmeng S. van, Olde Hartman, T.C., Das, E. Quantifying positive communication: doctor's language and patient anxiety in primary care consultations. Patient Education and Counseling: 2018, 10149), 1577-1584

\subsection{Statistical analysis}

Baseline differences between patient groups were evaluated using $t$-tests for continuous variables and $\chi$-squares for categorical variables.

Multilevel models with binary outcomes were used to assess differences in language use adjusted for clustering of GPs and patients. The Intraclass Correlation Coefficient (ICC) of the random factors GP and patient were 0.012 and 0.018 respectively, suggesting a minimal clustering of the data on the indicated levels. Patient and GP gender were included as potential confounding factors. The fixed factors as predictors of message directness (indirect vs. direct) were complaint type (MUS vs. MES), message content (positive vs. negative), the interaction term between complaint type and message content, and the potential confounding variables. Stratified analyses were performed in case of a significant interaction between the predictor variables.

Next, associations between message directness and anxiety were assessed with a hierarchical linear regression analysis. We first aggregated scores of directness for positive and negative messages per consultation. Indices for indirect (vs. direct) positive messages per consultation were created using the following formula: (direct positive-indirect positive messages) $\div$ (positive messages + negative messages), with indices closer to 1 indicating a relatively higher amount of direct positive messages in relation to the total amount of relevant messages. A similar approach is used in classical studies on persuasion [36] ; [37]. The index for direct positive messages is adjusted for the total amount of negative messages; it decreases when more negative messages are expressed in relation to the amount of positive messages, whereas it increases when relatively few negative messages are used. The formula thus corrects for the relative comparison between positive and negative message content. The same calculations were performed to create an index score for the directness of negative messages, i.e. (direct negative-indirect negative messages) $\div$ (positive messages + negative messages).

To test for differences in patient anxiety, a difference score comparing anxiety before and after the consultation was included as outcome variable. The potential confounders and complaint type (MUS or MES) were entered as predictors in the first model, index scores for directness of positive and negative messages were included in the second model, and interactions between complaint type and index scores in the third.

\section{RESULTS}

Two patients with MUS were excluded due to technical problems with the video recordings. This resulted in a total sample size of 41 MUS and 41 MES consultations from 18 GPs ( 9 males and 9 females, age $M=45.83, S D=10.38$ ), located in urban $(n=8)$ or rural $(n=10)$ areas with experience ranging between 2 and 43 years. Two GPs reported that no patient with MUS visited their practice during the video recordings. Demographic information of the patients is displayed in Table 1.

\section{[TABLE 1]}

In total, 2590 clauses were identified and coded, number per consultation varying from 2 to $89($ Mean $=32)$. As can be observed in Table 2, 1124 clauses had a positive message content, 1017 had negative content, and 449 were neutral description of symptoms. A quarter of the clauses were indirect $(n=653)$. With regard to the 
Stortenbeker, J.A., Houwen, J., Lucassen, P.L.B.J., Stappers, H.W., Assendelft, W.J.J., Dulmeng S. van, Olde Hartman, T.C., Das, E. Quantifying positive communication: doctor's language and patient anxiety in primary care consultations. Patient Education and Counseling: 2018, 10149), 1577-1584

consultation phase, 297 clauses were expressed during physical examination, 1149 during explanation of the diagnosis and 1144 during treatment recommendations. Language use during history taking was not included, because this research focused on judgmental expressions rather than question formulations of GPs.

\section{[TABLE 2]}

\subsection{Systematic variation in message directness for MUS versus MES}

Message directness was significantly associated with complaint type (MUS or MES) and message content. Messages were more likely to be direct (vs. indirect) when patients had MUS rather than MES, and when content was positive compared to negative. A significant interaction term between the two predictors indicated that GPs used different language for patients with MUS and MES (Fig. 1). Stratified analyses showed that when patients had MES, GPs were more likely to express direct formulations in negative rather than positive messages $(b=.65, S E=.16$, OR 1.91; $95 \%$ CI 1.42 to 2.59), while such difference in message directness was not observed for patients with MUS $(b=-.15, S E=.13$, OR .11; 95\% CI -.41 to .11). This indicates that the directness of a message was different depending on the content of the message for patients with MES, but not for patients with MUS. ${ }^{1}$

\section{[FIGURE 1]}

\subsection{MESSAGE DIRECTNESS IN RELATION TO PATIENT ANXIETY}

Two patients with MES that filled in less than $60 \%$ of the anxiety scale were removed from analyses. The average anxiety scores varied between 1.00 and 3.80 . The difference in anxiety before and after the consultation varied between -1.40 and 1.37, with higher scores indicating an increase in patient anxiety. As can be observed in Table 3, complaint type (MUS vs. MES) and the potential confounding variables were entered in the first regression model. This model appeared insignificant $(F(3$, $76)<1)$. Next, indices of direct positive and negative messages were added to the second model $\left(\mathrm{F}_{\text {change }}(2,74)=3.36, p=.040\right)$, which explained $9.5 \%$ of the variance. Although the index score for direct positive messages did not predict changes in patient anxiety $(b=-.14, S E=.22,95 \% \mathrm{CI}-0.58$ to 0.31$)$, it appeared that the index score for direct negative messages was a significant predictor for changes in patient anxiety ( $b=.67, S E=.30,95 \%$ CI 0.07 to 1.27 ). The more direct (vs. indirect) negative messages were expressed in consultations, the more anxious patient felt. Since the third model with the interaction terms between message directness and complaint type appeared not significant $\left(\mathrm{F}_{\text {change }}(2,72)<1\right)$, it was excluded from the final model. The relation between message directness and anxiety did not differ for patients with MUS or MES.

\section{[TABLE 3]}

\section{DISCUSSION AND CONCLUSION}

\subsection{Discussion}

This content analysis was the first to disentangle message content (what is said) from message directness (how it is said) in communication of physicians, and to assess 
Stortenbeker, J.A., Houwen, J., Lucassen, P.L.B.J., Stappers, H.W., Assendelft, W.J.J., Dulmeng S. van, Olde Hartman, T.C., Das, E. Quantifying positive communication: doctor's language and patient anxiety in primary care consultations. Patient Education and Counseling: 2018, 10149), 1577-1584

how differences message directness are related to changes in patient anxiety. Two key findings were identified. First, GPs changed the directness of a message depending on its content for patients with MES. These patients were more likely to receive indirect negative messages (e.g. "the thyroid was not normal" rather than "the thyroid was anomalous") and direct positive messages (e.g. "your back is looking good" rather than "your back is looking not bad"). GPs did not vary their language use for patients with MUS. The second key finding was that directness of messages turned out to be related to psychological wellbeing of patients, such that direct (as opposed to indirect) negative messages were associated with increased selfreported anxiety. This occurred equally for patients with MES and MUS. From this it can be concluded that slight differences in the directness of a negative messages relate patient outcomes. This knowledge is of utmost importance as it can be used to improve doctor-patient interactions.

There are two likely causes for the finding that GPs changed the directness of messages for patients with MES but not MUS. First, prior negative expectations of GPs about patients with MUS may have been translated into their language use. Patients with MUS are often perceived as difficult patients [20] and physicians experience difficulties when communicating with them [38]. It is possible that differences in language use reflect GPs' own discomfort in communicating with these patients. Another possibility is that physicians felt the urge to clearly formulate negative messages for patients with MUS using unambiguous and direct symptom explanations rather than indirect formulations as a face saving strategy [14] ; [39]. Second, unexplained symptoms are established as most likely cause after physical tests and examinations that exclude (potentially harmful) organic causes [40]. This diagnosis per exclusionem - based on what is not wrong - is perhaps reflected in the absence of a different message strategy in positive messages for patients with MUS. Recently, however, it has been argued that the nomenclature of unexplained symptoms should be based on positive diagnosis rather than exclusion of other possibilities [41]. The emphasis should be on what complaints the patient does have instead of which symptoms are not present.

The key finding that patients were more anxious after hearing direct negative messages is consistent with intuitive ideas of MUS experts [42] and quasiexperimental research on communication with patients with MUS that physicians should try to communicate positively [5]. When indirect formulations are used to express negative messages (comparable to 'not good'), relatively more positive wordings are expressed. The exact reversed concept is introduced ('good') and consequently activated and made more accessible in the patient's mind [43].These findings potentially reveal the role of communication in non-specific effects of the consultation.

The results of this study provide novel insights in doctor-patient interactions from a linguistic viewpoint. Where previous medical research failed to provide specific examples [42], empirical research did not distinguish between content and formulation [2,5][e.g. 2,5], and communication research mainly provided evidence from experimental settings with healthy volunteers [e.g. 11], this study was able to systematically disentangle which aspects of communication predict changes in patient anxiety in a quantitative, structural manner. The study provides clear-cut examples of how a positive communication style can be achieved in terms of message directness for patients with MUS with evidence from daily practice. 
Stortenbeker, J.A., Houwen, J., Lucassen, P.L.B.J., Stappers, H.W., Assendelft, W.J.J., Dulmeng S. van, Olde Hartman, T.C., Das, E. Quantifying positive communication: doctor's language and patient anxiety in primary care consultations. Patient Education and Counseling: 2018, 10149), 1577-1584

Other communication practices next to language use are also important predictors of patient outcomes. Extensive research has demonstrated the importance of generic interventions in doctor-patient interactions about MUS such as reassuring patients, giving tangible explanations and providing support [42]. Showing empathy with patients with MUS helps to lower patient anxiety and improve satisfaction [44]. Additionally, different types of explanations could also have important implications for patients with MUS [45] and the extent to which they accept the message [46]. This study adds to the current field of research by targeting a specific yet important aspect of communication rather than a more generic approach to communication. Even though this study reveals importance of varying language use in doctor-patient interactions, there are two major reasons why not all physician's negative messages should be expressed indirectly. First, the relation between language use and anxiety was based on a ratio of (in)direct positive and negative messages expressed during the course of the consultation. This suggests that in general, patients benefit from the use of indirect negative messages over direct ones. The current data, however, do not provide evidence for the amount of negative messages that should be expressed (in)directly during primary care consultations, and which contextual factors (e.g. patient concerns or individual preferences) might play a role. Second, previous research reveals that potentially differences in meaning can occur for messages with identical content expressed in a direct or indirect manner [47] ; [48]. Especially when the content is positive, indirect messages could convey a weakened meaning as opposed to direct ones. By altering the directness of a message, it must be considered that a slightly different message is conveyed.

This study has some limitations to consider. Since this study focused on evaluations of the GPs about patients rather than question formulations, language use related to history taking was not included. Yet subtle variations of question formulations can have important consequences for how patients present symptoms [49]. Future research should expand the scope of the current study by systematically analysing the role of question formulations during the history taking consultations about MUS. Similarly, clauses of patients were not addressed. Language use, however, is construed in the interaction between physician and patient. If patients formulate symptoms with certain words (e.g. "I am not feeling well"), physicians may tend to adapt the same formulation to explain symptoms (e.g. "because you are not feeling well, [...]"). Further work is needed to establish the role of patients in message formulations of physicians. Moreover, patients' direct responses to language use were not addressed, and, as a consequence, no causal relations could be established. Additional experimental research is desirable to test how messages with identical content can evoke different effects depending on how they are formulated. Finally, consultations of patients with unexplained symptoms were linked to MES consultations visiting the same GP and the same day, following a similar method performed by Salmon, Ring, Dowrick and Humphris [32]. It was not possible to match patients on the International Classification of Primary Care (ICPC) codes, subjective presentation of complaints, age, or gender. Future studies should strive for matching patients based on common socio-demographic factors.

\subsection{Conclusions}

Doctor-patient communication plays a pivotal role in recovery for patients with MUS. Previous studies showed that what a doctor says can have an effect on health outcomes. This study on naturalistic language in doctor-patient interactions shows 
Stortenbeker, J.A., Houwen, J., Lucassen, P.L.B.J., Stappers, H.W., Assendelft, W.J.J., Dulmeng S. van, Olde Hartman, T.C., Das, E. Quantifying positive communication: doctor's language and patient anxiety in primary care consultations. Patient Education and Counseling: 2018, 101(9), 7 1577-1584

that language, how it is said, also plays an important role in predicting patient anxiety. Even though GPs express more positive language for patients with MES (i.e., "good" rather than "not bad"), they do not have different message strategies for patients with MUS. Language, however, can have therapeutic effects for patients such that indirect negative messages are related to decreased patient anxiety.

\subsection{Practice implications}

The results of this study have direct implications for what language physicians should use during consultations, which is universal to many languages. Positive communication can be achieved by using more indirect negative messages in statements such as:

- "The treatment will not evoke positive outcomes" (instead of "It will evoke poor outcomes");

- "Your physical complaints are not improving" (instead of "Your physical complaints are persisting").

Very subtle changes in wordings can have a significant impact on emotions of patients. Physicians should be provided with tools for how to communicate in a more - but not overly - positive manner.

\section{Competing interests}

The authors declare that they have no competing interests.

\section{Ethical approval and consent to participate}

The data obtained for this study have been approved by the Ethics Committee of the Radboud University Medical Centre (file number 2015-1566). A written informed consent was obtained from all participants before entry into the study.

\section{Support}

The data collection of this work was supported by the Dutch public funding agency ZonMw (grant number 839110010). The funder had no influence on the analysis or publication.

\section{Acknowledgments}

We would like to thank Loes Jacobs for her help as a second coder.

\section{APPENDIX A.}

\section{Technical appendix}

\section{Coding procedure}

\section{Development of coding criteria}

Given the explorative nature of the study, no explicit coding criteria were existent. Therefore, a new codebook was developed in order to analyse language use. The first author (IS) first viewed a random selection of the video-recordings as a preparation for development of the codebook. An initial framework was developed based on these first observations. Next, linguistic literature on, for instance, the use of negations (Burgers et al., 2015; Haeseryn, Coppen \& de Vriend (2012) was gathered 
Stortenbeker, J.A., Houwen, J., Lucassen, P.L.B.J., Stappers, H.W., Assendelft, W.J.J., Dulmeng S. van, Olde Hartman, T.C., Das, E. Quantifying positive communication: doctor's language and patient anxiety in primary care consultations. Patient Education and Counseling: 2018, 10149), 7 1577-1584

to further define and specify the codebook. Categories were selected if relevant to language use theory or MUS communication. After five test-coding sessions, a second coder joined the study. The coder was first trained in identifying relevant clauses and distinguishing between categories. Then, the second coder independently performed the same coding strategy; reading the transcription, identifying different phases, underlining relevant clauses, and categorising each clause.

Simultaneous identification and selection of the relevant utterances appeared too cognitively exhausting, leading to weak tests of inter-coder reliability (due to overand undercoding). Therefore, the coding process was divided into two steps. Coders first focused on selection of relevant clauses, and then they categorised utterances selected by the first coder. Assigning one task at the same was expected to increase the change of a reliable analysis.

\section{Unit of analysis}

According to Krippendorff, the smallest unit of analysis possible must be selected to enable a reliable content analysis (Krippendorff, 2004). The recording/coding unit (i.e. unit of analysis) in the current study to identify message formulations were grammatical finite clauses, i.e. clauses that contain a finite, or conjugated, verb. As an example, the sentence "I want to refer you to a specialist, because your tiredness is not normal" can be divided into two clauses that contain a finite verb, namely [I want to refer you to a specialist] and [because your tiredness is not normal]. Utterances without finite verbs (e.g. exclamations such as “Good!") were also included as separate units of analysis.

\section{Coding procedure}

Judgmental expressions of the GPs about patients and their current medical situation were identified. These descriptions relate to comments about the physical or mental state of the patient during physical examination (e.g. "This looks tidy"), expressions that are related to the diagnosis or explanations the diagnosis (e.g. "Your physical complaints are indeed related to fatigue"), or judgmental expressions about treatment policy or expected treatment outcomes (e.g. "It is better to use a real fungus ointment", "The skin must improve within two weeks")

After having identified relevant clauses, both coders categorised the clauses as selected by the first coder $(n=503)$. The message content of the clause was indicated as either positive or negative. Clauses with positive message content refer to a positive evaluation or consequence for the patient (e.g. "It is looking very good"), and clauses with negative message content refer to descriptions that imply a negative evaluation or consequence for the patient (e.g. "It seems that your blood pressure is way too low"). Neutral clauses that referred to the naming of symptoms, either as objective observations (e.g. "I can see some red skin here") or expressed with clinical viewpoint (e.g. "The pain in your legs must be neurosympathic") were also coded. ${ }^{2}$ Next, the message directness was classified in terms of direct or indirect formulations. Indirect language was classified as containing syntactic or morphologic negations. Syntactic negations refer to constituents as negation elements such as 
Stortenbeker, J.A., Houwen, J., Lucassen, P.L.B.J., Stappers, H.W., Assendelft, W.J.J., Dulmeng S. van, Olde Hartman, T.C., Das, E. Quantifying positive communication: doctor's language and patient anxiety in primary care consultations. Patient Education and Counseling: 2018, 10149), 1577-1584

explicit ("not") and implicit ("none", "less") particles as negative markers, and morphologic negations are negative prefixes added to nouns, verbs, adverbs, or adjectives ("non-smoker", "incomplete"). Double negatives (e.g. "not unhealthy") were coded as both syntactic and morphologic. Finally, the consultation phase of utterances was noted down. Coders indicated whether evaluative descriptions were related to physical examination, (explanations of) diagnosis, or treatment recommendations.

\section{Statistical testing}

Multilevel models with binary outcomes were used to assess differences in message load, adjusted for clustering of GP (level 3) and patients (level 2). The Intraclass Correlation Coefficient (ICC) of the random factors GP and patient were 0.012 and 0.018 respectively, suggesting a minimal clustering of the data on the indicated levels. Patient gender was included as a potential confounding factor because men and women were not equally distributed among the MUS and MES groups, and gender of the GP was also included because male physicians tend to communicate differently from female physicians (Jefferson, Bloor, Birks, Hewitt, \& Bland, 2013), and men tend to use more indirect formulations than women (Newman, Groom, Handelman, \& Pennebaker, 2008). The fixed factors as predictors of message directness (direct vs. indirect) were complaint type (MUS vs. MES), message content (positive vs. negative), the interaction term between complaint type and message content, and the potential confounding variables. Stratified analyses were performed in case of a significant interaction between the predictor variables.

Next, associations between message directness and anxiety were assessed with a hierarchical linear regression analysis. We first aggregated scores of directness for positive and negative messages per consultation. Indices for direct (vs. indirect) positive messages per consultation were created using the following formula: (direct positive-indirect positive messages) $\div$ (positive messages + negative messages), with indices closer to 1 indicating a relatively higher amount of direct positive messages in relation to the total amount of relevant messages. A similar approach is used in classical studies on persuasion (; cf. Killeya \& Johnson, 1998 ; Sherman, Nelson \& Steele, 2000 ;). The index for direct positive messages is adjusted for the total amount of negative messages; it decreases when more negative messages are expressed in relation to the amount of positive messages, whereas it increases when relatively few negative messages are used. The formula thus corrects for the relative comparison between positive and negative message content. The same calculations were performed to create an index score for the directness of negative messages, i.e. (direct negative-indirect negative messages) $\div$ (positive messages + negative messages).

To test for differences in patient anxiety, a difference score comparing anxiety before and after the consultation was included as outcome variable. The potential confounders and complaint type (MUS or MES) were entered as predictors in the first model, index scores for directness of positive and negative messages were included in the second model, and interactions between complaint type and index 
Stortenbeker, J.A., Houwen, J., Lucassen, P.L.B.J., Stappers, H.W., Assendelft, W.J.J., Dulmeng S. van, Olde Hartman, T.C., Das, E. Quantifying positive communication: doctor's language and patient anxiety in primary care consultations. Patient Education and Counseling: 2018, 10149), 7 1577-1584

scores in the third. Analyses were conducted using IBM SPSS Statistics. An alpha level of 0.05 was used as a criterion for all statistical tests.

\section{Results: Additional table}

Systematic variation in message directness for MUS versus MES.

Table A1. Summary of the multilevel random intercept logistic regression for complaint type (MUS vs. MES) and message content (positive versus negative) predicting message directness (indirect vs. direct), corrected for confounder variables $(N=2121)$.

\begin{tabular}{|c|c|c|c|c|c|}
\hline & \multirow{2}{*}{ B (SE) } & \multicolumn{3}{|c|}{ 95\% CI for Odds Ratio } & \multirow{2}{*}{ Sig. } \\
\hline & & Lower & Odds ratio & Upper & \\
\hline Intercept & $-.63(.16)$ & & & & \\
\hline MUS vs. MES & $-.34(.17)$ & 0.51 & 0.71 & 0.99 & 0.042 \\
\hline Message content $^{\mathrm{a}}$ & $-.61(.16)$ & 0.40 & 0.54 & 0.74 & 0.000 \\
\hline Message content ${ }^{*}$ MUS vs. MES & $.74(.21)$ & 1.41 & 2.10 & 3.15 & 0.000 \\
\hline \multicolumn{6}{|c|}{ Confounders } \\
\hline GP gender (male vs. female) & $-.21(.15)$ & 0.60 & 0.81 & 1.09 & 0.160 \\
\hline Patient gender (male vs. female) & $.05(.14)$ & 0.79 & 1.05 & 1.39 & 0.726 \\
\hline \multicolumn{6}{|c|}{ ICC } \\
\hline GP (level 3) & 0.012 & & & & \\
\hline Patient (level 2) & 0.018 & & & & \\
\hline
\end{tabular}

${ }^{\mathrm{a}}$ Message content compared for positive versus negative content.

\section{REFERENCES}

[1] F. Benedetti Mechanisms of placebo and placebo-related effects across diseases and treatments Annu. Rev. Pharmacol. Toxicol., 48 (2008), pp. 33-60

[2] D. Varelmann, C. Pancaro, E.C. Cappiello, W.R. Camann Nocebo-induced hyperalgesia during local anesthetic injection Anesthesia Analgesia, 110 (3) (2010), pp. 868-870

[3] L. Vase, S. Baram, N. Takakura, H. Yajima, M. Takayama, T.J. Kaptchuk, S. Schou, T.S. Jensen, R. Zachariae, P. Svensson Specifying the nonspecific components of acupuncture analgesia Pain, 154 (9) (2013), pp. 1659-1667

[4] U. Bingel, V. Wanigasekera, K. Wiech, R. Ni Mhuircheartaigh, M.C. Lee, M. Ploner, I. Tracey The effect of treatment expectation on drug efficacy: imaging the analgesic benefit of the opioid remifentanil Sci. Transl. Med., 3 (70) (2011) (70ra14)

[5] K.B. Thomas General practice consultations: is there any point in being positive? $\mathrm{Br}$. Med. J. (Clin. Res. Ed.), 294 (6581) (1987), pp. 1200-1202

[6] D.D. Price, J. Craggs, G.N. Verne, W.M. Perlstein, M.E. Robinson Placebo analgesia is accompanied by large reductions in pain-related brain activity in irritable bowel syndrome patients Pain, 127 (1-2) (2007), pp. 63-72

[7] R. Crow, H. Gage, S. Hampson, J. Hart, A. Kimber, H. Thomas The role of expectancies in the placebo effect and their use in the delivery of health care: a systematic review Health Technol. Assess., 3 (3) (1999), pp. 1-96 
Stortenbeker, J.A., Houwen, J., Lucassen, P.L.B.J., Stappers, H.W., Assendelft, W.J.J., Dulmen, S. van, Olde Hartman, T.C., Das, E. Quantifying positive communication: doctor's language and patient anxiety in primary care consultations. Patient Education and Counseling: 2018, 101(9), 1577-1584

[8] A.J. Barsky, R. Saintfort, M.P. Rogers, J.F. Borus Nonspecific medication side effects and the nocebo phenomenon JAMA, 287 (5) (2002), pp. 622-627

[9] K.B. Thomas General practice consultations: is there any point in being positive? Br. Med. J. (Clin. Res. Ed.), 294 (6581) (1987), pp. 1200-1202

[10] P. Knipschild, A. Arntz Pain patients in a randomized trial did not show a significant effect of a positive consultation J. Clin. Epidemiol., 58 (7) (2005), pp. 708-713

[11] E.K. Porensky, B.D. Carpenter Breaking bad news: effects of forecasting diagnosis and framing prognosis Patient Educ. Couns., 99 (1) (2016), pp. 68-76

[12] C.A. Bigman, J.N. Cappella, R.C. Hornik Effective or ineffective: attribute framing and the human papillomavirus (HPV) vaccine Patient Educ. Couns., 81 (Suppl) (2010), pp. S70-S76

[13] H.H.J. Das, W. Jacobs Well-informed or IIl-informed? Reframing of potential treatment side effects and stigma consciousness affect cognitive performance among breast cancer patients (2018) manuscript in preparation

[14] C. Burgers, C.J. Beukeboom, L. Sparks How the doc should (not) talk: when breaking bad news with negations influences patients' immediate responses and medical adherence intentions Patient Educ. Couns., 89 (2) (2012), pp. 267-273

[15] A. Aamland, K. Malterud, E.L. Werner Patients with persistent medically unexplained physical symptoms: a descriptive study from Norwegian general practice BMC Fam. Pract., 15 (2014), p. 107

[16] P.F. Verhaak, S.A. Meijer, A.P. Visser, G. Wolters Persistent presentation of medically unexplained symptoms in general practice Fam. Pract., 23 (4) (2006), pp. 414-420

[17] P. Fink, M.S. Hansen, M.L. Oxhoj The prevalence of somatoform disorders among internal medical inpatients J. Psychosom. Res., 56 (4) (2004), pp. 413-418

[18] V. Arolt, M. Driessen, H. Dilling The Lubeck General Hospital Study. I: prevalence of psychiatric disorders in medical and surgical inpatients Int. J. Psychiatry Clin. Prac., 1 (3) (1997), pp. 207-216

[19] C.F. Dowrick, A. Ring, G.M. Humphris, P. Salmon Normalisation of unexplained symptoms by general practitioners: a functional typology Br. J. Gen. Pract., 54 (500) (2004), pp. 165-170

[20] S.R. Hahn Physical symptoms and physician-experienced difficulty in the physicianpatient relationship Ann. Intern. Med., 9 (Pt. 2) (2001), pp. 897-904

[21] A. Ring, C.F. Dowrick, G.M. Humphris, J. Davies, P. Salmon The somatising effect of clinical consultation: what patients and doctors say and do not say when patients present medically unexplained physical symptoms Soc. Sci. Med., 61 (7) (2005), pp. 1505-1515

[22] R.M. Epstein, C.G. Shields, S.C. Meldrum, K. Fiscella, J. Carroll, P.A. Carney, P.R. Duberstein Physicians' responses to patients' medically unexplained symptoms Psychosom. Med., 68 (2) (2006), pp. 269-276

[23] A.J. Barsky, J.F. Borus Somatization and medicalization in the era of managed care JAMA, 274 (24) (1995), pp. 1931-1934

[24] P. Salmon Conflict, collusion or collaboration in consultations about medically unexplained symptoms: the need for a curriculum of medical explanation Patient Educ. Couns., 67 (3) (2007), pp. 246-254

[25] J.M. Aiarzaguena, I. Gaminde, I. Clemente, E. Garrido Explaining medically unexplained symptoms: somatizing patients' responses in primary care Patient Educ. Couns., 93 (1) (2013), pp. 63-72

[26] C. Monzoni, M. Reuber Linguistic and interactional restrictions in an outpatient clinic: the challenge of delivering the diagnosis and explaining the aetiology of functional neurological problems F. Chevalier, J. Moore (Eds.), Producing and Managing Restricted Activitities: Avoidance and Withholding in Institutional Interaction, John Benjamins Publishing Company, Amsterdam (2015), pp. 239-270

[27] C. Burbaum, A.M. Stresing, K. Fritzsche, P. Auer, M. Wirsching, G. Lucius-Hoene Medically unexplained symptoms as a threat to patients' identity? A conversation analysis of patients' reactions to psychosomatic attributions Patient Educ. Couns., 79 (2) (2010), pp. 207-217

[28] K.J. Looper, L.J. Kirmayer Perceived stigma in functional somatic syndromes and comparable medical conditions J. Psychosom. Res., 57 (4) (2004), pp. 373-378 
Stortenbeker, J.A., Houwen, J., Lucassen, P.L.B.J., Stappers, H.W., Assendelft, W.J.J., Dulmeng S. van, Olde Hartman, T.C., Das, E. Quantifying positive communication: doctor's language and patient anxiety in primary care consultations. Patient Education and Counseling: 2018, 101(9), 1577-1584

[29] L.A. Page, S. Wessely Medically unexplained symptoms: exacerbating factors in the doctor-patient encounter J. R. Soc. Med., 96 (5) (2003), pp. 223-227

[30] J. Houwen, P.L. Lucassen, H.W. Stappers, P.J. Assendelft, T.C. van Dulmen, S. Olde Hartman Medically unexplained symptoms: the person, the symptoms and the dialogue Fam. Prac., 34 (2) (2017), pp. 245-251

[31] P. Salmon, A. Ring, G.M. Humphris, J.C. Davies, C.F. Dowrick Primary care consultations about medically unexplained symptoms: how do patients indicate what they want? J. Gen. Intern. Med., 24 (4) (2009), pp. 450-456

[32] P. Salmon, A. Ring, C.F. Dowrick, G.M. Humphris What do general practice patients want when they present medically unexplained symptoms, and why do their doctors feel pressurized? J. Psychosom. Res., 59 (4) (2005), pp. 255-260 (discussion 261-2)

[33] C.D. Spielberger, R.L. Gorsuch, P.R. Lushene, P.R. Vagg, G.A. Jacobs Manual for the State-Trait Anxiety Inventory Consulting Psychologists Press Inc. (2016), p. 1983

[34] C. Burgers, C.J. Beukeboom, L. Sparks, V. Diepeveen How (not) to inform patients about drug use: use and effects of negations in Dutch patient information leaflets Pharmacoepidemiol. Drug Saf., 24 (2) (2015), pp. 137-143

[35] W. Haeseryn, P. Coppen, F. de Vriend Elektronische Versie Algemene Nederlandse Spraakkunst [Electronic Version General Dutch Grammar] (2012) http://ans.ruhosting.nl/eans/index.html. (Accessed 7 April 2016)

[36] D.A.K. Sherman, L.D. Nelson, C.M. Steele Do messages about health risks threaten the self? Increasing the acceptance of threatening health messages via self-affirmation Pers. Soc. Psychol. B, 26 (9) (2000), pp. 1046-1058

[37] L.A. Killeya, B.T. Johnson Experimental induction of biased systematic processing: the directed-thought technique Pers. Soc. Psychol. Bull., 24 (1) (1998), pp. 17-33

[38] T.C. Olde Hartman, H. Woutersen-Koch, H.E. Van der Horst Medically unexplained symptoms: evidence, guidelines, and beyond Br. J. Gen. Prac., 63 (617) (2013), pp. 625626

[39] R. Giora, N. Balaban, O. Fein, I. Alkabets Negation as positivity in disguise H.L. Colston, A. Katz (Eds.), Figurative Langauge Comprehension: Social and Cultural Influences, Erlbaum, Hillsdale, NJ (2004), pp. 233-258

[40] B.D. Cash, W.D. Chey Irritable bowel syndrome - an evidence-based approach to diagnosis Aliment. Pharmacol. Ther., 19 (12) (2004), pp. 1235-1245

[41] A. Evens, L. Vendetta, K. Krebs, P. Herath Medically unexplained neurologic symptoms: a primer for physicians who make the initial encounter Am. J. Med., 128 (10) (2015), pp. 1059-1064

[42] M. Heijmans, T.C. Olde Hartman, E. van Weel-Baumgarten, C. Dowrick, P.L. Lucassen, C. van Weel Experts' opinions on the management of medically unexplained symptoms in primary care. A qualitative analysis of narrative reviews and scientific editorials Fam. Pract., 28 (4) (2011), pp. 444-455

[43] C.J. Beukeboom, C. Finkenauer, D.H. Wigboldus The negation bias: when negations signal stereotypic expectancies J. Pers. Soc. Psychol., 99 (6) (2010), pp. 978-992

[44] F. Derksen, J. Bensing, A. Lagro-Janssen Effectiveness of empathy in general practice: a systematic review Br. J. Gen. Pract., 63 (606) (2013), pp. e76-84

[45] L. Morton, A. Elliott, J. Cleland, V. Deary, C. Burton A taxonomy of explanations in a general practitioner clinic for patients with persistent medically unexplained physical symptoms Patient Educ. Couns., 100 (2) (2017), pp. 224-230

[46] M. den Boeft, D. Huisman, L. Morton, P. Lucassen, J.C. van der Wouden, M.J. Westerman, H.E. van der Horst, C.D. Burton Negotiating explanations: doctor-patient communication with patients with medically unexplained symptoms-a qualitative analysis Fam. Pract., 34 (1) (2017), pp. 107-113

[47] R. Giora, N. Balaban, O. Fein, I. Alkabets Negation as positivity in disguise H.L. Colston, A. Katz (Eds.), Figurative Language Comprehension: Social and Cultural Influences, Erlbaum, Hillsdale, NJ (2004), pp. 233-258

[48] N. Kamoen, M.B.J. Mos, W.F.S. Dekker A hotel that is not bad isn't good. The effects of valence framing and expectation in online reviews on text, reviewer and product appreciation J. Pragmat., 75 (2015), pp. 28-43 
Stortenbeker, J.A., Houwen, J., Lucassen, P.L.B.J., Stappers, H.W., Assendelft, W.J.J., Dulmeng S. van, Olde Hartman, T.C., Das, E. Quantifying positive communication: doctor's language and patient anxiety in primary care consultations. Patient Education and Counseling: 2018, 10149), 7 1577-1584

[49] J. Heritage, J.D. Robinson, M.N. Elliott, M. Beckett, M. Wilkes Reducing patients' unmet concerns in primary care: the difference one word can make J. Gen. Intern. Med., 22 (10) (2007), pp. 1429-1433

1 Analyses were also considered with consultation phase added to the model. A significant three-way interaction was observed between consultation phase (diagnosis vs. treatment), complaint type and message content $(b=-1.09, \mathrm{SE}=.44$, OR $0.34 ; 95 \% \mathrm{Cl} 0.14$ to 0.80$)$. Stratified analyses per consultation phase showed a significant interaction between complaint type and message content during diagnosis $(b=-1.26, \mathrm{SE}=.34, \mathrm{OR} 0.28 ; 95 \%$ $\mathrm{Cl} 0.15$ to 0.55 ). Differences in GPs' messages were thus mainly existent during diagnosis

2 Neutral utterances (objective observations and clinical viewpoint) are excluded from analyses because they do not contain judgmental expressions.

\section{TABLES AND FigURE}

Table 1. Comparison of patients' (MUS and MES) demographic information.

\begin{tabular}{|c|c|c|c|}
\hline & $\operatorname{MUS}(n=41) M(S D)$ & $\operatorname{MES}(n=41) M(S D)$ & Sig. \\
\hline Age & 50.68 & 54.48 & 0.340 \\
\hline & $N(\%)$ & $N(\%)$ & \\
\hline Sex & & & 0.043 \\
\hline Male & $12(29.3)$ & $21(51.2)$ & \\
\hline Female & $29(70.7)$ & $20(48.8)$ & \\
\hline Level of education $^{*}$ & & & 0.242 \\
\hline Primary school & $5(12.2)$ & $2(4.9)$ & \\
\hline Secondary school & $24(58.5)$ & $20(48.8)$ & \\
\hline (Applied) University & $12(29.3)$ & $18(43.9)$ & \\
\hline First visit of symptoms ${ }^{*}$ & $13(38.7)$ & $16(41.0)$ & 0.386 \\
\hline Currently working & $19(46.3)$ & $19(46.3)$ & 1.00 \\
\hline
\end{tabular}

* One missing value for level of education and two missing values for first visit of symptoms for patients with MES.

Table 2. Message content and directness for patients with MUS and MES $(N=2590)$.

\begin{tabular}{|c|c|c|c|c|}
\hline & Quote* & $\begin{array}{c}\text { MUS } n \\
(\%)\end{array}$ & $\begin{array}{c}\text { MES } n \\
(\%)\end{array}$ & $\begin{array}{c}\text { Total } N \\
(\%)\end{array}$ \\
\hline \multicolumn{5}{|c|}{ Message content } \\
\hline Positive & "This looks tidy" & \begin{tabular}{|l}
598 \\
$(40.4)$
\end{tabular} & $\begin{array}{l}526 \\
(47.4)\end{array}$ & $\begin{array}{l}1124 \\
(43.2)\end{array}$ \\
\hline Negative & "The toes are a bit cold" & $\begin{array}{l}634 \\
(42.8)\end{array}$ & $\begin{array}{l}383 \\
(34.5)\end{array}$ & $\begin{array}{l}1017 \\
(39.3)\end{array}$ \\
\hline
\end{tabular}


Stortenbeker, J.A., Houwen, J., Lucassen, P.L.B.J., Stappers, H.W., Assendelft, W.J.J., Dulmeng S. van, Olde Hartman, T.C., Das, E. Quantifying positive communication: doctor's language and patient anxiety in primary care consultations. Patient Education and Counseling: 2018, 10149), 7 1577-1584

\begin{tabular}{|c|c|c|c|c|}
\hline & Quote $^{*}$ & $\begin{array}{c}\text { MUS } n \\
(\%)\end{array}$ & $\begin{array}{c}\text { MES } n \\
(\%)\end{array}$ & $\begin{array}{c}\text { Total } N \\
(\%)\end{array}$ \\
\hline Neutral & "“The pain must be neurosympathic” & $\begin{array}{l}248 \\
(16.8)\end{array}$ & $\begin{array}{l}201 \\
(18.1)\end{array}$ & $449(17.6)$ \\
\hline \multicolumn{5}{|c|}{ Message directness } \\
\hline Indirect & $\begin{array}{l}\text { "Your back is not completely } \\
\text { straight" }\end{array}$ & $\begin{array}{l}394 \\
(26.6) \\
\end{array}$ & $\begin{array}{l}259 \\
(23.3) \\
\end{array}$ & $653(25.2)$ \\
\hline Direct & $\begin{array}{l}\text { "You are improving from a physical } \\
\text { perspective" }\end{array}$ & $\begin{array}{l}2196 \\
(73.4)\end{array}$ & $\begin{array}{l}2331 \\
(76.6)\end{array}$ & $\begin{array}{l}1937 \\
(74.8)\end{array}$ \\
\hline \multicolumn{5}{|c|}{ Consultation phase } \\
\hline Physical examination & $\begin{array}{l}\text { "I do not feel a really intense } \\
\text { resistance" }\end{array}$ & $\begin{array}{l}158 \\
(10.7)\end{array}$ & $\begin{array}{l}139 \\
(12.5)\end{array}$ & $297(11.5)$ \\
\hline Diagnosis & $\begin{array}{l}\text { "Your physical complaints are related } \\
\text { to fatigue" }\end{array}$ & $\begin{array}{l}737 \\
(49.8)\end{array}$ & $\begin{array}{l}412 \\
(37.1) \\
\end{array}$ & $\begin{array}{l}1149 \\
(44.4)\end{array}$ \\
\hline $\begin{array}{c}\text { Treatment } \\
\text { recommendation }\end{array}$ & $\begin{array}{l}\text { "It is better to use a real fungus } \\
\text { ointment" }\end{array}$ & $\begin{array}{l}585 \\
(39.5)\end{array}$ & $\left(\begin{array}{l}559 \\
(50.4)\end{array}\right.$ & $\begin{array}{l}1144 \\
(44.2)\end{array}$ \\
\hline
\end{tabular}

*Quotes are derived from the corpus.

$N B$ : Clauses expressed during history taking were not included.

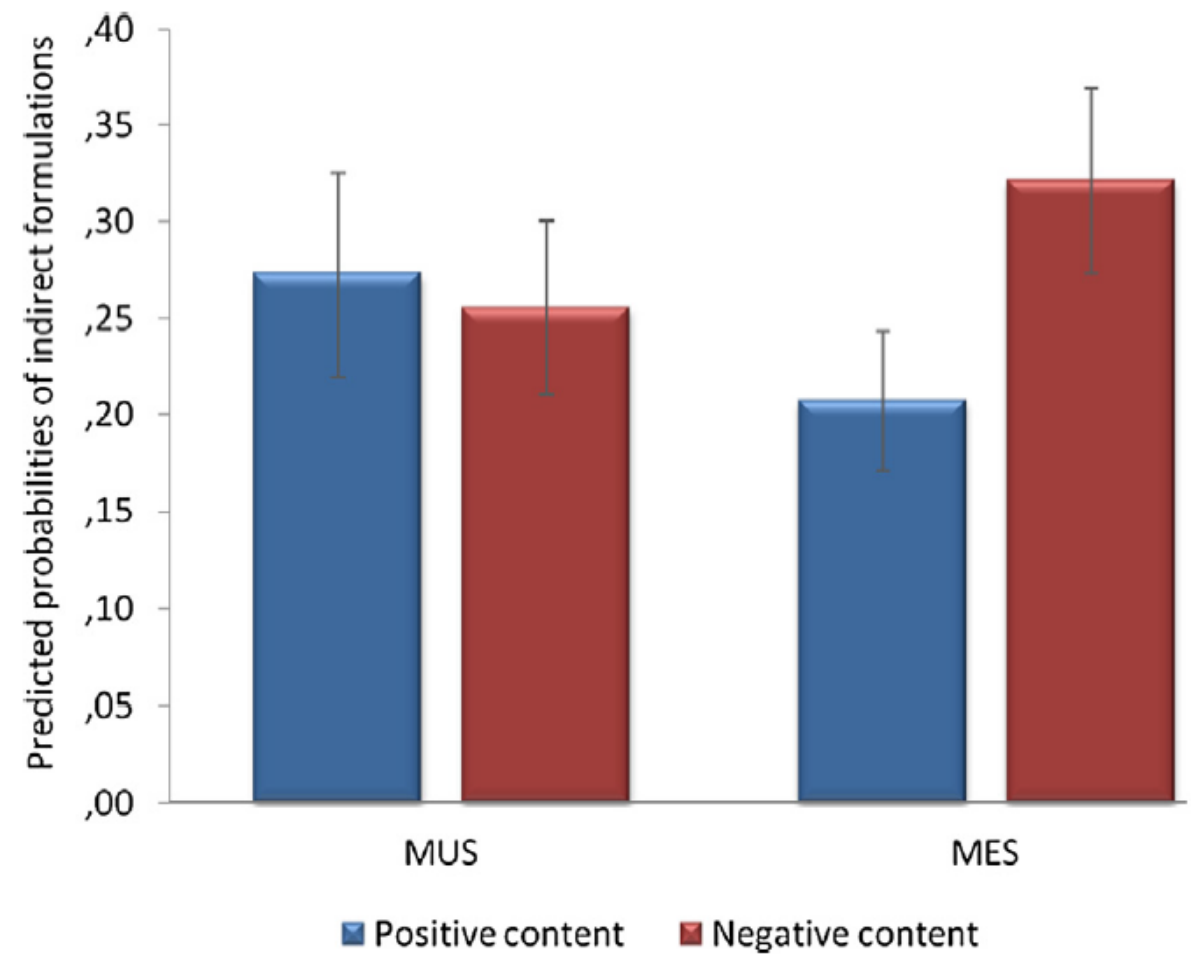

Fig. 1. Interaction between message content (positive versus negative) and complaint type (MUS versus MES) for indirect formulations. 
Stortenbeker, J.A., Houwen, J., Lucassen, P.L.B.J., Stappers, H.W., Assendelft, W.J.J., Dulmen, S. van, Olde Hartman, T.C., Das, E. Quantifying positive communication: doctor's language and patient anxiety in primary care consultations. Patient Education and Counseling: 2018, 101(9), 1577-1584

Table 3

Summary of linear regression analysis for variables concerning complaint type (MUS vs. MES) (model 1 and 2) and indexed direct positive and negative messages (model 2), corrected for confounder variables $(N=80)$.

\begin{tabular}{|c|c|c|c|c|}
\hline & \multicolumn{2}{|l|}{ Model 1} & \multicolumn{2}{|l|}{ Model 2} \\
\hline & $B(S E)$ & $95 \% \mathrm{CI}$ & $\mathrm{B}(\mathrm{SE})$ & $95 \% \mathrm{CI}$ \\
\hline MUS vs. MES & $.09(.11)$ & $.12 ; 0.31$ & $.16(.11)$ & $-.05 ; 0.38$ \\
\hline Direct positive messages & & & $-.14(.22)$ & $-.58 ; 0.31$ \\
\hline Direct negative messages & & & $.67(.30)^{*}$ & $.07 ; 1.27$ \\
\hline Confounders & & & & \\
\hline GP gender ( $m$ vs. $\mathrm{f}$ ) & $-.06(.11)$ & $-.27 ; 0.16$ & $.05(.11)$ & $-.18 ; 0.27$ \\
\hline Patient gender ( $\mathrm{m}$ vs. f) & $.06(.11)$ & $-.17 ; 0.28$ & $.04(.11)$ & $-.18 ; 0.25$ \\
\hline$\Delta R^{2}$ & 0.01 & & 0.08 & \\
\hline$\Delta F$ & 0.33 & & $3.36^{*}$ & \\
\hline
\end{tabular}

